\section{Nasobiliary tube placement: how to accomplish oral-to-nasal transfer}

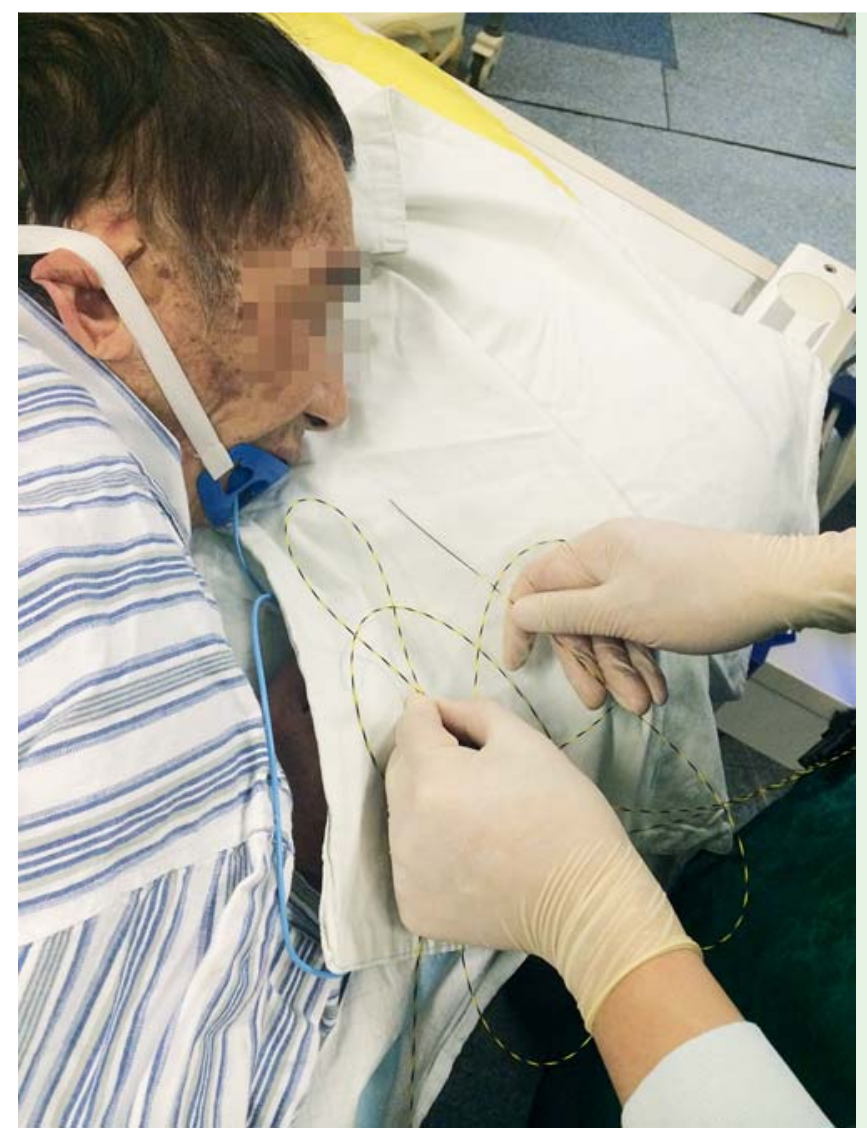

Fig. 1 A snare with one or two loops is made from the guidewire at about $40 \mathrm{~cm}$ from the soft tip.

We would like to present our experience of nasobiliary tube (NBT) transfer. A description of this technique, called the guidewire maneuver, follows ( $\bullet$ Video 1 ). The patient changes from the prone to the left lateral decubitus position while con-

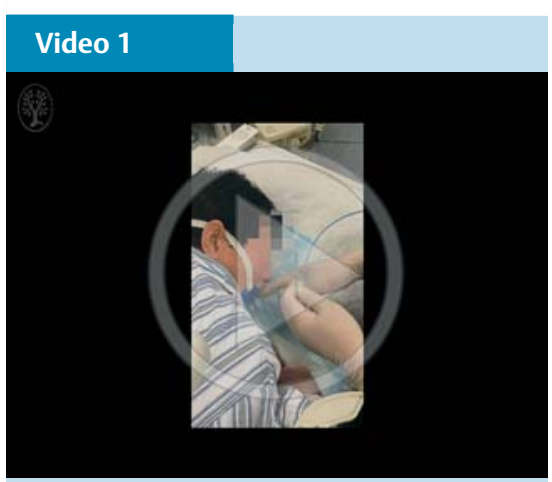

Nasobiliary tube transfer: the guidewire maneuver. tinuing to bite on the mouthpiece. The guidewire (Jagwire, 0.035 in; Boston Scientific, Natick, Massachusetts, USA) previously used for endoscopic retrograde cholangiopancreatography (ERCP) can be reused instead of a transfer tube.

First, a snare with one or two loops is made from the guidewire at about $40 \mathrm{~cm}$ from the soft tip ( $\bullet$ Fig. 1 ). The endoscopist uses the left hand to grasp the snare and insert it through the mouthpiece to the posterior wall of oropharynx as far as possible. At the same time, two fingers of the right hand are used to introduce the soft end of the guidewire into the oropharynx through the nasal cavity. When the soft tip of the guidewire has been inserted into the snare about 20 to $25 \mathrm{~cm}$ from the nostril, the snare should be retrieved, and the soft end of the guidewire can be pulled out of the oral cavity simultaneously. Then, the tip of the NBT is passed over the soft end of the guidewire and advanced for about $20 \mathrm{~cm}$. Finally, the endoscopist pinches the NBT firmly so as to prevent the guidewire from slipping from the NBT and pulls them out of the nasal cavity together.

We have used this technique for more than 3 years with great success. It avoids accidental trauma to the endoscopist's fingers and damage to the NBT. At the same time, nasal bleeding seldom occurs, and the patient feels little discomfort because of the tiny diameter of the guidewire. Compared with other reported techniques [1-3], we think that our unique method offers a simpler and safer way to perform the last step of NBT placement.

Endoscopy_UCTN_Code_TTT_1AR

Competing interests: None

\section{Ke Li, Yong-Hui Huang, Xue-Biao Huang, Hong Chang, Wei Yao, Yao-Peng Zhang}

Department of Gastroenterology, Peking University Third Hospital, Beijing, China

\section{References}

1 Baron TH. Transnasal endoscopy to facilitate nasobiliary tube placement: a simple and safe technique to avoid injury to the endoscopist. Endoscopy 2010; 42 (Suppl. 02): E323

2 Ustündağü Y, Baysal C, Boyacioğülu $S$ et al. Use of a new mouthpiece in placing a nasobiliary drainage tube. Endoscopy 1998; 30 : $3-4$

3 Itoi T, Sofuni A, Itokawa F et al. Role of endoscopic nasobiliary drainage: indication and basic technique. Digest Endosc 2006; 18 (Suppl. 01): S105-S109

\section{Bibliography}

DOI http://dx.doi.org/

10.1055/s-0034-1392633

Endoscopy 2015; 47: E420

(c) Georg Thieme Verlag KG

Stuttgart · New York

ISSN 0013-726X

\section{Corresponding author}

\section{Yong-Hui Huang, MD}

Department of Gastroenterology

Peking University Third Hospital

49 North Garden Road

Haidian district

Beijing 100191

China

Fax: +86-10-6206-6807

huangyonghui@medmail.com.cn 